See discussions, stats, and author profiles for this publication at: https://www.researchgate.net/publication/337804029

\title{
Framework of 5S Quality Management for University Ecosystem to Achieve Green Campus
}

Article in International Journal of Scientific Research and Management · December 2019 Dol: 10.18535/ijsm/v7i12.em01

CITATIONS

6 authors, including:

Nashirah Abu Bakar

Universiti Utara Malaysia

63 PUBLICATIONS 312 CITATIONS

SEE PROFILE

(A) Noriza Abd Aziz

Universiti Utara Malaysia

6 PUBLICATIONS 1 CITATION

SEE PROFILE

Some of the authors of this publication are also working on these related projects:

Structural Equation Modelling View project

Computational Islamic Finance View project
Noraziah che arshad

Universiti Utara Malaysia

16 PUBLICATIONS 46 CITATIONS

SEE PROFILE

6. Uzaki Kiyotaka

Oita University

14 PUblications 52 Citations

SEE PROFILE 


\title{
Framework of 5S Quality Management for University Ecosystem to Achieve Green Campus
}

\author{
Nashirah Abu Bakar', Sofian Rosbi ${ }^{2}$, Azizi Abu Bakar ${ }^{3}$, Noraziah Che Arshad ${ }^{4}$, Noriza Abd Aziz ${ }^{5}$ and \\ Kiyotaka Uzaki ${ }^{6}$ \\ 1,3,4,5 Islamic Business School, College of Business, \\ Universiti Utara Malaysia, Kedah, Malaysia \\ ${ }^{2}$ School of Mechatronic Engineering, Universiti Malaysia Perlis, Malaysia \\ ${ }^{6}$ Faculty of Economics, Oita University, Japan
}

\begin{abstract}
:
The objective of this paper is to evaluate framework of $5 \mathrm{~S}$ quality management for university ecosystem to achieve green campus. The main elements in $5 \mathrm{~S}$ quality management are sort (seiri), set in order (seiton), shine (seiso), standardize (seiketsu), and sustain (shitsuke). The 5S quality improvement method is defined as a methodology that results in a workplace that is clean, uncluttered, safe, and well organized to help reduce waste and optimize productivity. It's designed to help build a quality work environment, both physically and mentally. The function of $5 \mathrm{~S}$ method is to improve process efficiency and safety, reduces waste, prevents errors and defects. This paper focuses on implementation of $5 \mathrm{~S}$ in university environment that mainly on areas of education system, finance management, man power arrangement, energy saving operation and building maintenance. In the same time, this paper propose evaluation of green $5 \mathrm{~S}$ quality management in considering effect to environmental issues. The novelty of this framework is it provides academic institutional about standard operational for implementing quality management that considering environmental issues and efficient procedure for proses in management of university.
\end{abstract}

Keywords: Quality management, 5S, framework, University ecosystem, Green environment.

\section{Introduction}

5S initially based on the Japanese acronyms of seiri (sort), seiton (set in order), seiso (shine), seiketsu (standardize), and shitsuke (sustain) is used for quality management that aims to organize the workplace effectively, clean, maintain and do a good job (Osada, 1991). Takashi Osada is the author who developed the framework of $5 \mathrm{~S}$. The important of $5 \mathrm{~S}$ practices is to reduce costs by maximizing process efficiency, effectiveness and performance through the establishment and maintenance of a high-quality, clean working environment (Suarez-Barraza and Ramis-Pujol, 2012; Hirano, 1995; Ho, 1999; Liker, 2004; Liker and Hoseus, 2008). 5S is an outstanding practice implement in Japanese organizations in order to improve efficiency, strengthen performance and provide continuous improvement in all segments of the organization. In the current organization management was driven organization to adopt those practices, programs or methods which help facilitate continuous improvement in services. One of the keys to stay competitive is the ability to implement significant improvements throughout the organization and supply network (Attri, et al., 2017). Thus, 5S are essential practices to apply in organization in order to continuous improvement efficiency of the organization. However, 5S practice is not an easy task because it is required a drastic change in the attitude of employees and culture of the organizations. Thus, this study introduces the framework of $5 \mathrm{~S}$ quality management for university ecosystem to achieve green campus.

This paper focuses on implementation of $5 \mathrm{~S}$ in university environment that mainly on areas of education system, finance management, man power arrangement, energy saving operation and building maintenance. In the same time, this paper proposes evaluation of green $5 \mathrm{~S}$ quality management in considering effect to environmental issues. 


\section{Literature review}

5S practices was developed by Takashi Osada in early 1980. This management philosophy was derived from Toyota Production System (TPS) and was widely dispersed by several projects of the International Motor Vehicle (Womack and Jones, 1996; Monden, 1998: Randhawa and Ahuja, 2017). Therefore many organizations try to apply 5S practices. For example Ishijima et al., (2016) investigate the 5S practice and the reduction of patients' waiting time at outpatient departments of hospitals in Tanzania. This study has proved that the effectiveness of the $5 \mathrm{~S}$ approach in improving the working environment and reducing patients' waiting time at outpatient departments in Tanzania hospital. Gupta, et al., (2015) shows that 5S have major benefits in the form of tools searching time. This study found that searching time from shop floor has been reduced from 40 minutes to 5 minutes.

Study by Gapp, et al. (2008) found several key concepts behind the Japanese approach to 5S management. These findings demonstrate the importance of both the technical (visible) and philosophical (invisible) approaches required for each of the $5 \mathrm{~S}$ components and are discussed in a managerial rather than cultural framework. Then, Park, et al., (2012) investigate 5S practice in multinational organizations analyzed, along with a group of drivers and inhibitors responsible for enhancing or blocking the successful implementation of the 5S. Ho, et al., (1995) examine 205 manufacturing and 106 services firms in the UK as well as 16 leading companies from Japan found that $5 \mathrm{~S}$ practices provides an essential total quality environment which is an important base for implementing total quality management successfully. Ghodrati and Zulkifli (2013) show that $5 \mathrm{~S}$ is an effective tool for improvement of organizational performance, regardless of organization type, size, its production or its service. Consequently, 5S techniques would strongly support the objectives of organization to achieve continuous improvement and higher performance.

The 5S practice is seen as an effective technique that can improve housekeeping, environmental performance, health and safety standards in an integrated holistic way. Ab Rahman, et al. (2010) found that companies perform excellent while implement $5 \mathrm{~S}$ practice, but there are a few weaknesses that still need to be considered such as arrangement of the documents, tool and equipment. Rashmi, et al., (2018) show that $5 \mathrm{~S}$ is an effective tool for improvement of organization's working environment and work culture. Pratik (2017) demonstrate that implementation of 5S in the organization was successfully in achieve a proper a workplace management for better use of working area; time saving cost saving from waste and unwanted materials; and increased morale of the workers due to enhancement of working environment.

Todorovic and Cupic (2017) suggests that 5S can improves operation and profitability of organizations in the short and medium term. Implementation of $5 \mathrm{~S}$ practices is required in order to produce a safety environment, properly marking and labelling of the working place (Filip and Marascu-Klein, 2015). Implementation of $5 \mathrm{~S}$ can improvement the environmental performance especially on the housekeeping health and safety. Besides that $5 \mathrm{~S}$ also can improve the quality, productivity and working conditions in organizations (Shaikh, et al., 2015).

Lyp-Wronska and Tyczynski (2018) suggest that if company required to generate more profits is necessary to reduce waste, such as all activities that do not bring benefits. They suggested that proper determination of the area in the hall and machine for the employee is an important issue for maintaining production continuity. Besides that the proper use of human resources. Each employee must know exactly what is required of him and how to perform the tasks ordered. Adequate training also will increase the productivity of employees.

Young (2014) review the use of 5S in healthcare services 5S can be applied in healthcare services with beneficial effects such as cleaner, organized, efficient workplaces for enhanced safety and increased productivity; reduction of inventory and supply costs and recapturing of valuable spaces and minimizing overhead costs. Lamprea and Carreno (2015) investigate the impact of $5 \mathrm{~S}$ on the quality, productivity, industrial security and organizational climate in the manufacturing area of Small and Medium Enterprises (SMEs) in Colombia show the existence of a positive relationship between the study factors and the implementation of the $5 \mathrm{~S}$ practices.

\section{Framework of 5S quality management in academic institution to achieve green campus}

This study developed framework for addressed quality management that occurs in academic institution. Figure 1 shows area of quality management that need to focus in academic institution for green 5S. The six main areas of focus are managing education system, energy saving, recycling, financial management, maintenance and environmental preservation. All of these areas are core component in developing green 
campus. Therefore, all of this area need proper system of management to improve the level of efficiency for operation in university. One of the approach is using plan-do-act -check method as shown in Figure 2. The loop of improvement starting with planning procedure for the problems and proposing solutions. Second stage involving testing of planning with practical implementation to real problems. Then, the outcome is evaluated to improve the system. Fourth elements in loop of quality improvement is act which is implement best solution for system with the feedback to complete the continuous loop.

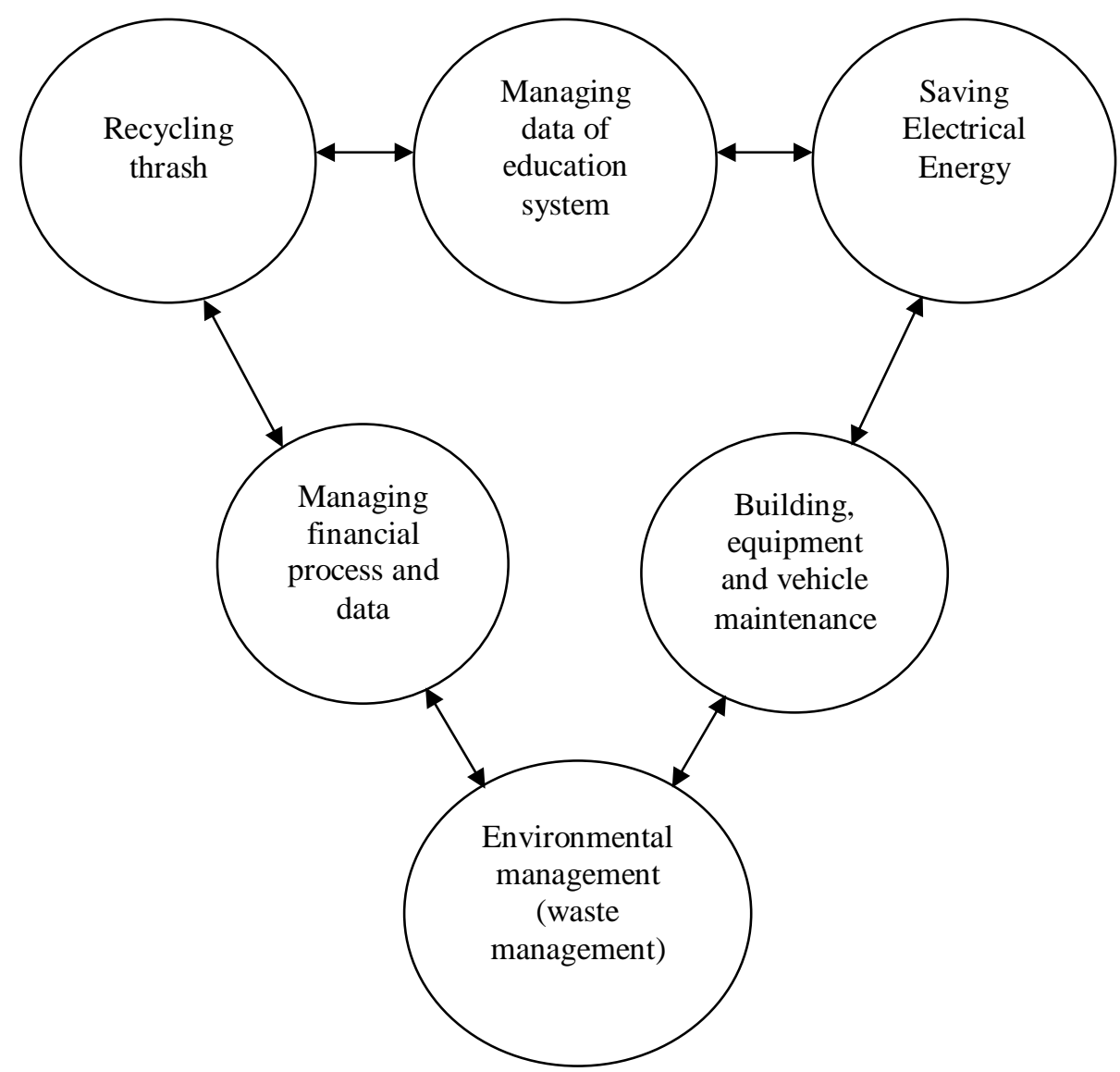

Figure 1: Six areas of focus for quality management in academic institution to achieve green campus

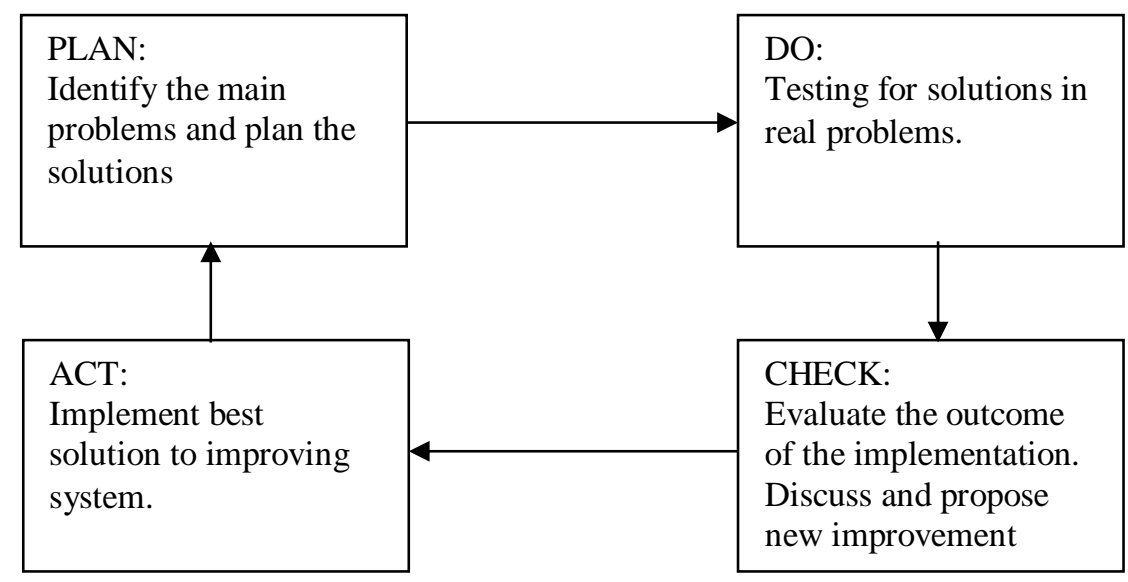

Figure 2: Continuous loop for quality improvement

Next, this study proposed framework of implementation for focus department in higher education provider to generate sustainable environmental eco-system. In this framework, quality improvement method plays an important role for achieving green and sustainable of university operational transaction procedure. 


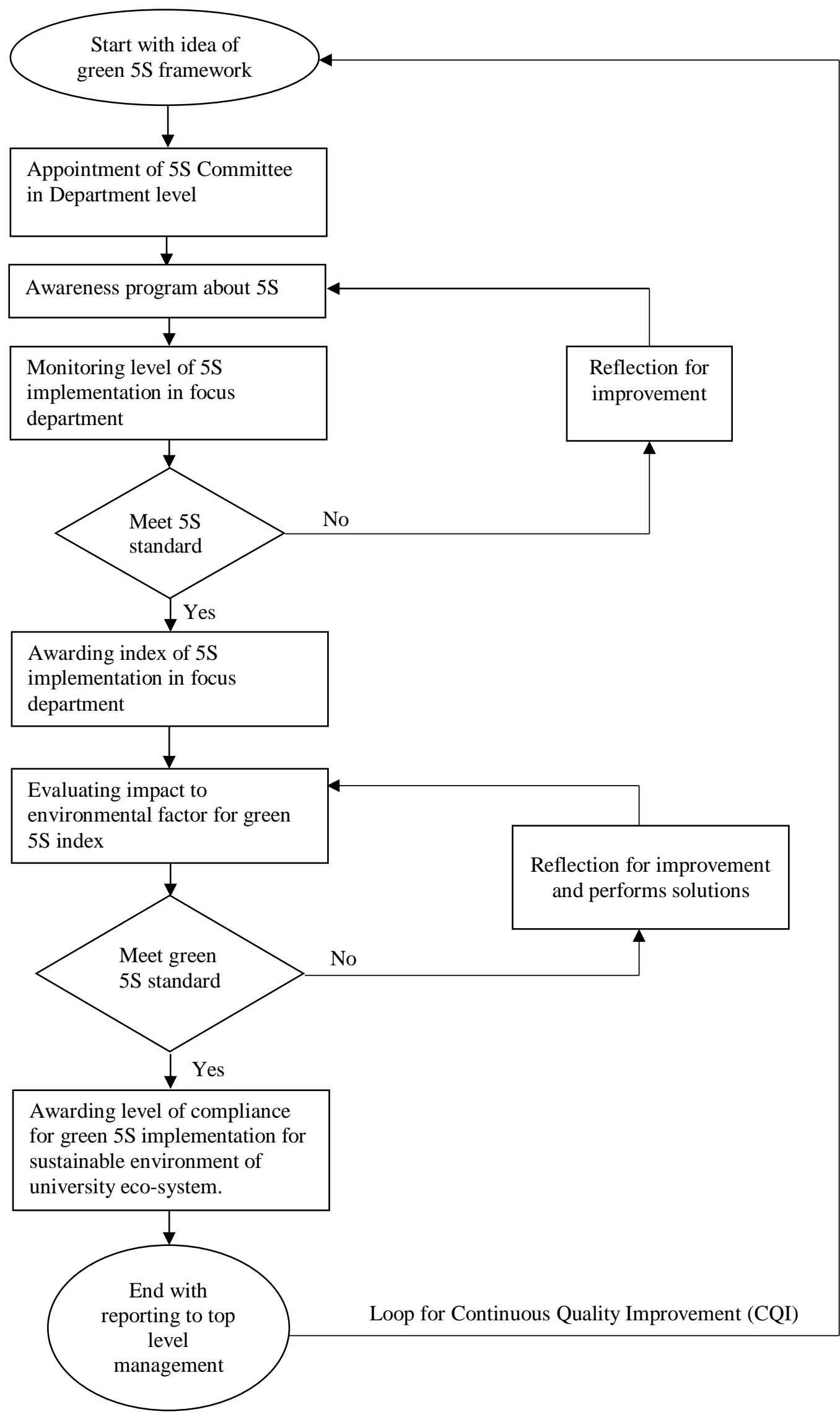

Figure 3: Framework of quality management for $5 \mathrm{~S}$ implementation in university environment

Then, this study developed 5S implementation framework in micro-level in each of department. The method of $5 \mathrm{~S}$ is defined as an approach that give outcome of workplace that is clean, uncluttered, safe, and well organized to help reduce waste and optimize productivity of operational process. The $5 \mathrm{~S}$ method is 
developed to help build a quality work environment, both physically and mentally. Figure 4 shows level of implementation for $5 \mathrm{~S}$ quality improvement with considering environmental issues.

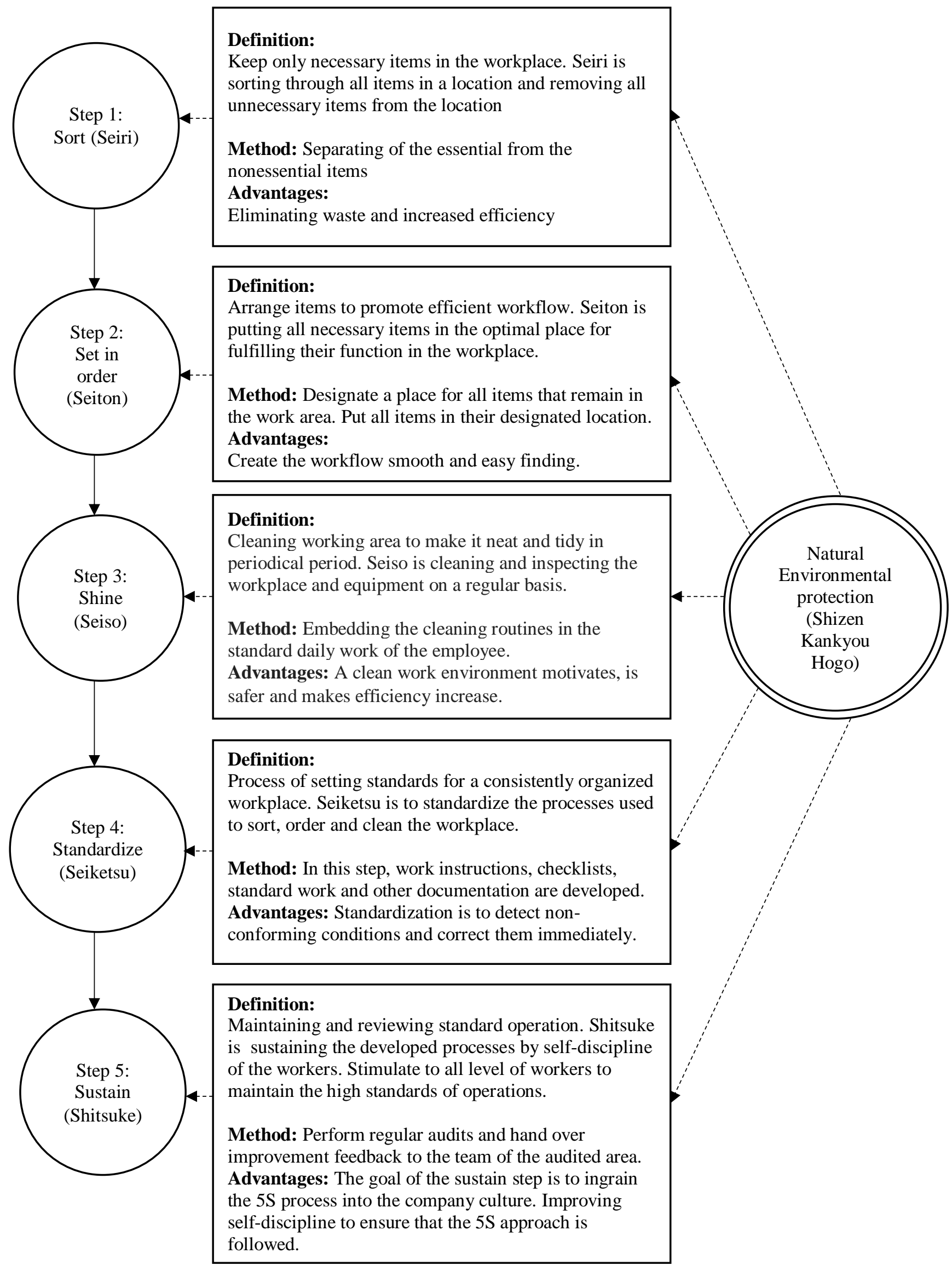

Figure 4: Quality improvement using 5S method with environmental concern 
Furthermore, this study analyzed the significant advantages of green 5S method with implementation in higher education institutions. Figure 5 shows the benefit of implementing green $5 \mathrm{~S}$ quality management in university.

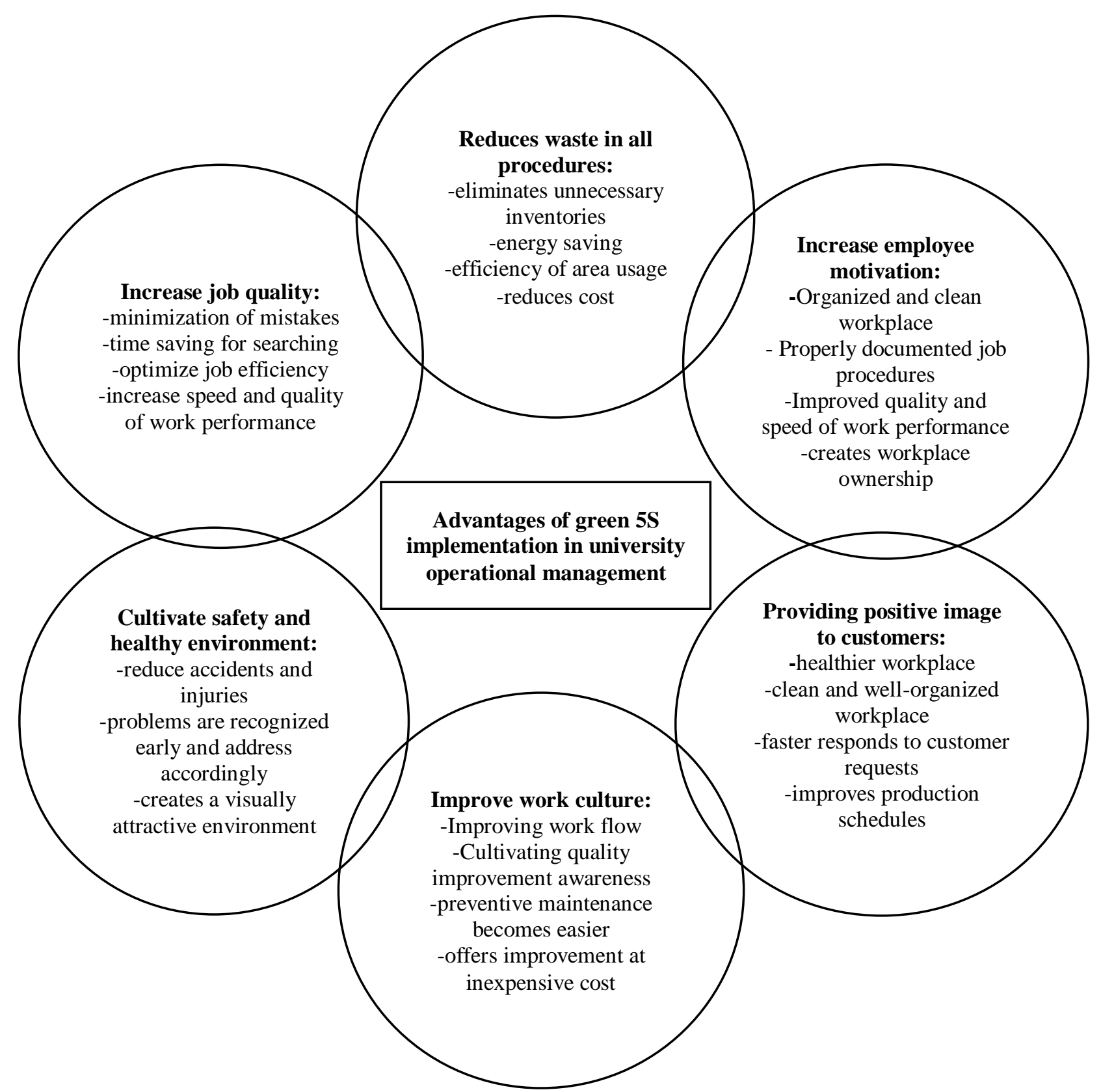

Figure 5: Advantages of implementing 5S green for quality management

\section{Conclusion}

This study developed framework of green $5 \mathrm{~S}$ for quality management to achieve green campus of sustainable ecosystem in university. Green $5 \mathrm{~S}$ is combination of quality management with concern of protecting natural environment. Implementation of green $5 \mathrm{~S}$ in university contributes to following advantages:

(i) Improves organizational efficiency.

(ii) Reduces waste in all processes.

(iii) Improves speed and quality of work performance.

(iv) Improves safety at workplace.

(v) Increasing awareness of environmental issue.

(vi) Increase total productivity.

(vii) Problems are recognized better and mistakes reduced. 
The framework of green $5 \mathrm{~S}$ contributes to better workplace with considering in protecting natural environment and in the same time trying reducing operational cost in term of job time, job efficiency and waste reduction.

\section{Acknowledgement}

This work was supported by the Development and Ecosystem Research Grant Scheme under Center for Testing, Measurement and Appraisal (CeTMA), Universiti Utara Malaysia (UUM).

\section{References}

[1] Ab Rahman, M.N., Khamis, N.K. and Mohd Zain, R. (2010). Implementation of 5S Practices in the Manufacturing Companies: A Case Study. American Journal of Applied Sciences, 7(8), 1182-1189.

[2] Attri, R., Singh, B. and Mehra, S. (2017). Analysis of interaction among the barriers to 5S implementation using interpretive structural modeling approach. Benchmarking: An International Journal, 24(7), 1834-1853.

[3] Filip, F.C. and Marascu-Klein, V. (2015). The 5S lean method as a tool of industrial management performances. IOP Conference Series: Materials Science and Engineering, 1-6.

[4] Gapp, R., Fisher, R. and Kobayashi, K. (2008). Implementing 5S within a Japanese context: an integrated management system. Management Decision, 46(4), 565-579.

[5] Ghodrati, A. and Zulkifli, N. (2013). The impact of 5S implementation on industrial organizations performance. International Journal of Business and Management Invention, 2(3), 43-49.

[6] Gupta, A., Verma, S. and Gupta, S. (2015). An application of 5S concept to organize the workplace at a small scale manufacturing company. International Journal of Engineering Sciences \& Research Technology, 713-728.

[7] Hernandez Lamprea, E.J. and Camargo Carreno, Z.M. (2015). Impact of 5S on productivity, quality, organizational climate and industrial safety in Caucho Metal Ltda. Ingeniare. Revista Chilena Dei, 23(1), 107-117.

[8] Hirano, H. (1995). 5 Pillars of the Visual Workplace: The Sourcebook for 5 'S Implementation, Tokyo: Productivity Press.

[9] Ho, S., Cicmil, S. and Fung, C. (1995). The Japanese 5-S practice and TQM training. Training for Quality, 3 (4), 19-24.

[10] Ho, S. (1999). 5-S practice: the first step towards total quality management. Total Quality Management, 10(3), 345-56.

[11] Ishijima, H., Eliakimu, E. and Mshana, J. (2016). The "5S" approach to improve a working environment can reduce waiting time. The TQM Journal, 28(4), 664-680.

[12] Liker, J. (2004), The Toyota Way, New York, NY; Simon \& Schuster Inc.

[13] Liker, J. and Hoseus, M. (2008), The Toyota Culture: The Heart and Soul of the Toyota Way, New York, NY: McGraw-Hill.

[14] Lyp-Wronska, K. and Tyczynski, B. (2018) Analysis of the 5S method in production enterprise case study. MATEC Web of Conferences, 183, 1-7.

[15] Monden, Y. (1998), Toyota Production System - An Integrated Approach to Just-in-Time, 3rd ed., New York, NY: Engineering and Management Press, CRC Press, Taylor and Francis Group, A Productivity Press Group, Institute of Industrial Engineers.

[16] Osada, T. (1991), The 5S's: Five Keys to a Total Quality Environment. Tokyo: Asian Productivity Organisation.

[17] Park, S., Lee, S., Suarez-Barraza, M. and Ramis-Pujol, J. (2012). An exploratory study of 5S: a multiple case study of multinational organizations in Mexico. Asian Journal on Quality, 13(1), 77 99.

[18] Pratik, A. (2017). Application of 5-S Technique in Manufacturing Industries in Simple Ways: A Case Study. International Journal of Computer Science and Information Technology Research, 5(4), 91-96.

[19] Randhawa, J. and Ahuja, I. (2017). 5S - a quality improvement tool for sustainable performance: literature review and directions. International Journal of Quality \& Reliability Management, 34(3), 334-361. 
[20] Rashmi K.R, Balaji, K.V.A. and Yashwanth H.S. (2018). A study of implementation of 5S in an electronic manufacturing firm in Mysuru. International Research Journal of Engineering and Technology, 5(6), 2051-2056.

[21] Shaikh, S., Noor Alam, A., Naseem Ahmed, K., Ishtiyak, S. and Hasan, S. Z. (2015). Implementation of 5S Practices in a Small Scale Organization: A Case Study. International Journal of Engineering and Management Research, 5(2), 130-135.

[22] Suarez-Barraza, M. and Ramis-Pujol, J. (2012). An exploratory study of 5S: a multiple case study of multinational organizations in Mexico. Asian Journal on Quality, 13(1), 77-99.

[23] Todorovic, M. and Cupic, M. (2017). How Does 5s Implementation Affect Company Performance? A Case Study Applied to a Subsidiary of a Rubber Goods Manufacturer from Serbia. Engineering Economics, 28(3), 311-322.

[24] Womack, J.P. and Jones, D.T. (1996). Lean Thinking: Banish Waste and Create Wealth in Your Corporation, New York, NY: Simon \& Schuster.

[25] Young, F.Y.F. (2014). The use of 5S in healthcare services: A literature review. International Journal of Business and Social Science, 5(10(1)), 240-248. 